\title{
Estimación del número de fallecimientos evitables por COVID-19 en relación con las medidas restrictivas adoptadas en Europa
}

\author{
José A. Cernuda-Martínez ${ }^{1 *}$ y Andrea Fernández-García² \\ ${ }^{1}$ Universidad de Oviedo, Facultad de Enfermería, Gijón, España; ${ }^{2}$ Servicio de Salud, Principado de Asturias, España
}

\begin{abstract}
Resumen
Introducción: En diciembre de 2019 surgió un nuevo coronavirus en Wuhan, China, que se ha convertido en un problema de salud global. Objetivo: Estimar cuántos fallecimientos diarios atribuibles a COVID-19 por cada 100000 habitantes se podrían haber evitado si se hubiese llevado a cabo cada una de las cinco medidas restrictivas al momento del diagnóstico del primer caso, así como estimar un modelo de regresión lineal múltiple predictivo del número de fallecimientos por cada 100000 habitantes. Métodos: Se realizó un modelo de regresión lineal simple entre los días transcurridos desde el primer caso diagnosticado de COVID-19, la implantación de cada una de las cinco medidas llevadas a cabo por los 39 países europeos estudiados, el número de camas hospitalarias por 1000 habitantes (variables independientes) y el número de fallecimientos por COVID-19 por 100000 habitantes. Resultados: Por cada día transcurrido desde el primer caso notificado de COVID-19 hasta la adopción de las medidas restrictivas, fallecieron entre $0.611(p=0.004)$ y $1.863(p=0.000)$ pacientes por cada 100000 habitantes, dependiendo de la medida implementada. Conclusiones: Las medidas restrictivas y el distanciamiento social, así como la celeridad de su instauración, son necesarios para lograr el descenso del número de contagios de COVID-19 y su mortalidad.
\end{abstract}

PALABRAS CLAVE: COVID-19. Mortalidad. Salud pública. Virus. Prevención y control.

\section{Estimation of the number of preventable COVID-19 deaths in relation to the restrictive measures adopted in Europe}

\begin{abstract}
Introduction: In December 2019, a new coronavirus emerged in Wuhan, China, which has become a global health problem. Objectives: To estimate how many daily COVID-19 deaths per 100,000 population could have been avoided if each one of five restrictive measures had been implemented at the time the first case was diagnosed, and to estimate a multiple linear regression model predictive of the number of deaths per 100,000 population. Methods: $A$ simple linear regression was performed between the days elapsed since the first COVID-19 diagnosed case, implementation of each one of the five restrictive measures carried out by the 39 European studied countries, the number of hospital beds per 1,000 population (independent variables) and the number of COVID-19 deaths per 100,000 population. Results: For each day elapsed from the first COVID-19 reported case to the adoption of restrictive measures, between $0.611(p=0.004)$ and $1.863(p=0.000)$ patients died per 100,000 population, depending on the implemented measure. Conclusions: Restrictive measures and social distancing, as well as promptness of their implementation, are necessary for achieving a decrease in COVID-19 infections and mortality.
\end{abstract}

KEY WORDS: COVID-19. Mortality. Public health. Virus. Prevention and control.

Correspondencia:

*José A. Cernuda-Martínez

E-mail: jacernudam@gmail.com

0016-3813/๑ 2020 Academia Nacional de Medicina de México, A.C. Publicado por Permanyer. Este es un artículo open access bajo la licencia CC BY-NC-ND (http://creativecommons.org/licenses/by-nc-nd/4.0/).
Fecha de recepción: 02-11-2020

Fecha de aceptación: 05-11-2020

DOI: $10.24875 / G M M .20000798$
Gac Med Mex. 2021;157:281-287

Disponible en PubMed

www.gacetamedicademexico.com 


\section{Introducción}

En diciembre de 2019 surgió un nuevo coronavirus en Wuhan, China, que se ha convertido en un problema de salud mundial: ${ }^{1}$ SARS-CoV-2, perteneciente a la misma familia que SARS y MERS-CoV, todos responsables de infecciones zoonóticas, el primero de COVID-19 y el tercero, del síndrome respiratorio de Oriente Medio. ${ }^{2}$

SARS-CoV-2 es un virus con genoma de ARN monocatenario positivo, de aproximadamente $30 \mathrm{~kb}$, que tiene de 74 a $99 \%$ de coincidencia con la cadena del coronavirus del pangolín (Manis javanica) y del murciélago herradura (Rhinolophus sinicus), ${ }^{1,3-5}$ Las secuencias del genoma de SARS-CoV-2 son similares a las de SARS-CoV, sin embargo, existen ciertas diferencias como la falta de la región codificante para la proteína 8 en SARS-CoV-2, lo que podría resultar en una menor patogénesis en comparación con SARS-CoV. ${ }^{6}$

La transmisión de SARS-CoV-2 se produce de persona a persona a través de las gotas respiratorias generadas durante la tos o los estornudos de una persona infectada. En hospitales y recintos cerrados pueden formarse aerosoles, de mayor tamaño, con una capacidad de contagio mayor, en los que el virus perdura varias horas, de ahí la necesidad de restringir el contacto entre las personas para evitar la propagación del virus. ${ }^{7}$

\section{Objetivos}

- Estimar cuántos fallecimientos diarios atribuibles a COVID-19 por cada 100000 habitantes se podrían haber evitado si al momento del diagnóstico del primer caso se hubiese llevado a cabo cada una de las cinco medidas restrictivas establecidas por los países europeos.

- Estimar un modelo de regresión lineal múltiple predictivo del número de fallecimientos atribuibles a COVID-19 por cada 100000 habitantes a partir de las cinco medidas restrictivas.

\section{Métodos}

Se diseñó un estudio ecológico en agosto de 2020 en relación con 39 países europeos. El criterio de inclusión fue el acceso a los datos de todas las medidas implantadas que conformaron el estudio. Se estableció como punto de partida la fecha del primer diagnóstico oficial de COVID-198 y se cuantificaron los días desde su acontecimiento hasta la implantación de cinco medidas: ${ }^{9}$

- Cierre de fronteras.

- Cierre de comercio no esencial.

- Cierre de locales de ocio y hostelería.

- Prohibición de eventos y concentraciones.

- Supresión de la enseñanza presencial.

Se obtuvo la tasa de fallecimientos debidos a COVID-19 por cada 100000 habitantes de cada uno de los 39 países al 20 de junio de 2020,10 así como el número de camas hospitalarias por cada 1000 habitantes. ${ }^{11,12}$

\section{Análisis estadístico}

Se realizó un modelo de regresión lineal simple de la relación entre cada una de las variables independientes (días transcurridos desde el primer caso hasta el cierre de fronteras, días transcurridos desde el primer caso hasta el cierre de comercio no esencial, días transcurridos desde el primer caso hasta el cierre de locales de ocio y hostelería, días transcurridos desde el primer caso hasta la prohibición de eventos y concentraciones, días transcurridos desde el primer caso hasta la supresión de la enseñanza presencial y número de camas hospitalarias por cada 1000 habitantes) y la variable dependiente (tasa de fallecimientos debidos a COVID-19 por cada 100000 habitantes), para conocer el número de fallecimientos por 100000 habitantes que se podrían haber evitado cada día si las medidas restrictivas se hubiesen llevado a cabo en el momento del diagnóstico del primer caso.

Por otro lado, se realizó un modelo de regresión lineal simple de la relación entre la tasa de fallecimientos por COVID-19 y el número de camas hospitalarias disponibles, así como un modelo predictivo de regresión lineal múltiple entre el número de fallecimientos por cada 100000 habitantes (variable dependiente) y los días transcurridos desde el primer caso hasta la prohibición de eventos y concentraciones, ya que la Organización Mundial de la Salud señala que el distanciamiento físico y la higiene de manos son las mejores medidas preventivas..$^{13}$ Este modelo se ajustó por las demás variables independientes, mediante el método de selección del mejor modelo a partir de todas las ecuaciones. Para seleccionar el modelo final se empleó el criterio $\mathrm{Cp}$ de Mallows y se eligió el que presentaba un valor más bajo. 
Se consideró un nivel de significación con un valor de $\mathrm{p}<0.05$ y un índice de confianza de $95 \%$. Para valorar externamente la fiabilidad del modelo se procedió a estudiar la pérdida de predicción mediante método de contracción (shrinkage), consistente en el cálculo de la diferencia entre el cuadrado de coeficiente de correlación múltiple del modelo estimado en el grupo de derivación $\left(R^{2}\right)$ y el cuadrado del coeficiente de correlación simple entre el valor predicho con el modelo estimado en el grupo de derivación y la variable dependiente $Y$, calculado en el grupo de validación $\left(\mathrm{r}^{2}\right)$. Se asumió como aceptable una diferencia $\leq 0.1$. El análisis se realizó con el programa Stata versión 15.

\section{Resultados}

En la Tabla 1 se indica la fecha en la que tuvo lugar el primer diagnóstico oficial de COVID-19 en cada uno de los 39 países europeos analizados, los días transcurridos hasta la puesta en marcha de cada una de las cinco medidas restrictivas, el número de fallecimientos por COVID-19 por 100000 habitantes y el número de camas hospitalarias disponibles por cada 1000 habitantes.

En la Tabla 2 se muestra el coeficiente b obtenido tras la regresión lineal entre la variable independiente y cada una de las variables dependientes. Cada coeficiente $b$ expresa el número de fallecimientos diarios por cada 100000 habitantes que se habrían evitado si cada medida preventiva se hubiese adoptado el día del primer diagnóstico de COVID-19.

En la Tabla 3 se describen las variables incluidas en el modelo predictivo, así como sus intervalos de confianza de $95 \%$ y el valor $p$. El valor de la $\mathrm{Cp}$ de Mallows fue de 3.04 , el valor de la $\mathrm{R}^{2}$ ajustada fue de 0.538 y el valor de la pérdida de predicción (diferencia entre $R^{2}$ y $r^{2}$ o shrinkage) fue de $-1.209 \times 10^{-8}$.

\section{Discusión}

El objetivo de este estudio fue estimar cuántos fallecimientos diarios por COVID-10 por cada 100000 habitantes se podrían haber evitado si cada medida se hubiese tomado en el momento del diagnóstico del primer caso. A tenor de los resultados de este estudio, la no adopción de cada una de las medidas restrictivas analizadas causa un aumento de 0.611 a 0.929 fallecimientos por 100000 habitantes por cada 24 horas de retraso en la instauración de estas desde el diagnóstico oficial del primer caso. Este número de fallecimientos evitables es estadísticamente significativo.

El Colegio Imperial del Reino Unido mostró que la combinación del aislamiento de los casos y la cuarentena voluntaria durante tres meses podría prevenir $31 \%$ de las muertes, en comparación con una epidemia sin ninguna medida de control. Añadir el distanciamiento social de las personas de 70 años o más durante cuatro meses aumentaría $49 \%$ de las muertes evitadas. Se consideró que la combinación de aislamiento de casos, cuarentena doméstica, distanciamiento social de toda la población y cierres de escuelas y universidades es la combinación más efectiva para reducir el número de reproducción a un valor cercano a uno. ${ }^{14}$

Aunque las medidas de prevención y control más exhaustivas y estrictas son más efectivas para la contención de COVID-19, en algún momento el efecto incremental de agregar otra medida restrictiva es mínimo y debe contrastarse con los efectos negativos colaterales, como las consecuencias sociales y económicas para las comunidades que han estado sujetas a las medidas por periodos prolongados, lo que también podría llevar a un aumento de la carga sobre la salud en general. ${ }^{15}$

Para el control de la epidemia en Europa, algunos investigadores definieron tres escenarios basados en modelos matemáticos que predicen de manera bastante precisa la proyección de la epidemia y la demanda de recursos sanitarios durante el tiempo de la curva exponencial: ${ }^{16}$

- Sin restricciones de movilidad.

- Con restricciones parciales.

- Con restricciones completas que solo permiten la actividad de servicios esenciales.

Sobre esos tres escenarios se predice el impacto de la evolución de la epidemia sobre el número de casos y quienes requerirán hospitalización convencional o ingreso en una unidad de cuidados intensivos. De ahí también deriva la recomendación de aplicar estas restricciones a la movilidad en función del número de casos en la región, a partir del cual se definen dos tipos de áreas:

- Área tipo A, con $\geq 100$ casos por 100000 habitantes en la última semana, donde se recomienda establecer un cierre completo de la actividad durante un mínimo de 15 a 21 días.

- Área tipo B, con < 100 casos por 100000 habitantes, en la que se recomienda realizar un confinamiento parcial y reducir a $30 \%$ las actividades y a $25 \%$ la movilidad interna. 


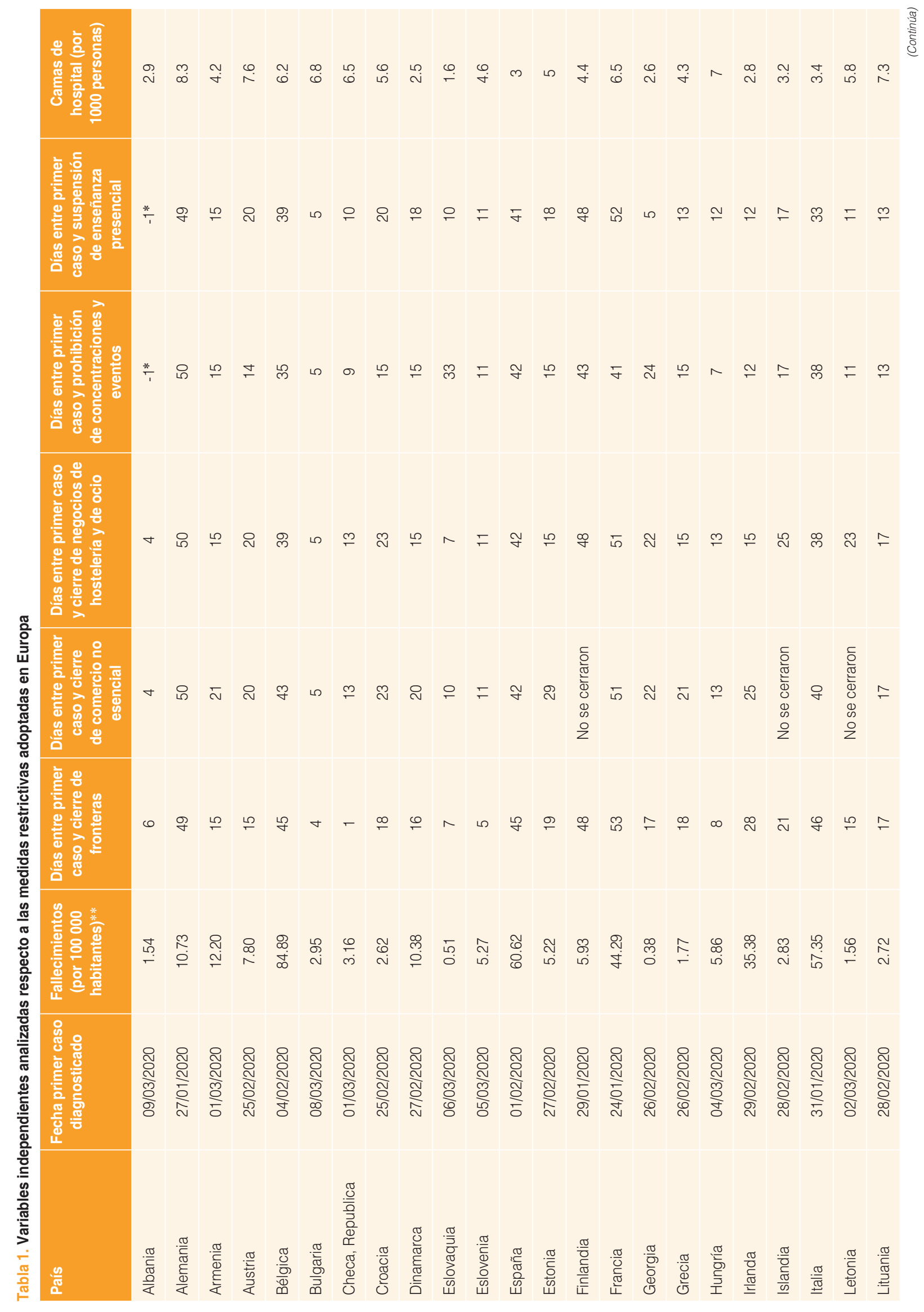




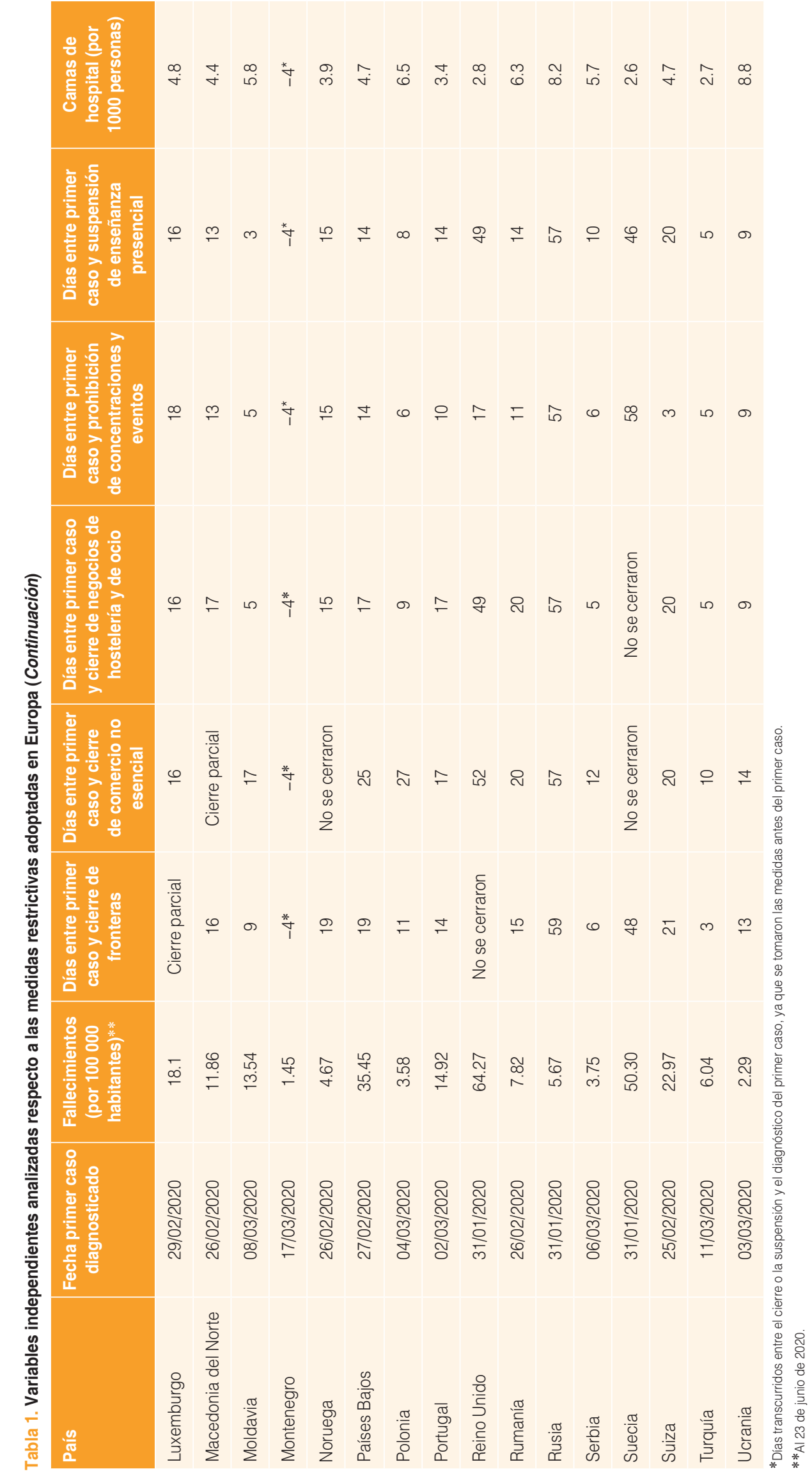


Tabla 2. Coeficientes b de la regresión lineal simple entre cada variable independiente y la variable dependiente (fallecimientos atribuibles a COVID-19 por 100000 habitantes)

\begin{tabular}{|c|c|c|c|c|}
\hline \multirow{2}{*}{$\begin{array}{l}\text { Variable } \\
\text { independiente }\end{array}$} & \multirow[t]{2}{*}{ Coeficiente b } & \multicolumn{2}{|c|}{ IC $95 \%$} & \multirow[t]{2}{*}{$p$} \\
\hline & & $\begin{array}{l}\text { Límite } \\
\text { inferior }\end{array}$ & $\begin{array}{l}\text { Límite } \\
\text { superior }\end{array}$ & \\
\hline $\begin{array}{l}\text { Días entre el primer } \\
\text { caso diagnosticado y } \\
\text { el cierre de fronteras }\end{array}$ & 0.780 & 0.446 & 1.114 & $0.000 *$ \\
\hline $\begin{array}{l}\text { Días entre el primer } \\
\text { caso diagnosticado y } \\
\text { el cierre de comercios } \\
\text { no esenciales }\end{array}$ & 0.929 & 0.512 & 1.347 & $0.000 *$ \\
\hline $\begin{array}{l}\text { Días entre el primer } \\
\text { caso diagnosticado } \\
\text { y el cierre de locales } \\
\text { de ocio y hostelería }\end{array}$ & 0.739 & 0.350 & 1.127 & $0.000 *$ \\
\hline $\begin{array}{l}\text { Días entre el primer } \\
\text { caso diagnosticado } \\
\text { y la prohibición } \\
\text { de eventos y } \\
\text { concentraciones }\end{array}$ & 0.611 & 0.208 & 1.015 & $0.004 *$ \\
\hline $\begin{array}{l}\text { Días entre el primer } \\
\text { caso diagnosticado } \\
\text { y la suspensión de la } \\
\text { enseñanza presencial }\end{array}$ & 0.786 & 0.427 & 1.145 & $0.000 *$ \\
\hline $\begin{array}{l}\text { Camas hospitalarias } \\
\text { por cada } 1000 \\
\text { habitantes }\end{array}$ & -2.348 & -6.072 & 1.376 & 0.209 \\
\hline
\end{tabular}

Tabla 3. Coeficientes de las variables del modelo estimado de fallecimientos evitables por COVID-19 y medidas restrictivas

\begin{tabular}{|c|c|c|c|c|}
\hline \multirow{2}{*}{$\begin{array}{l}\text { Variable } \\
\text { independiente } \\
\text { incluida/constante } \\
\text { del modelo }\end{array}$} & \multirow[t]{2}{*}{ Coeficiente b } & \multicolumn{2}{|c|}{ IC $95 \%$} & \multirow[t]{2}{*}{$\mathbf{P}$} \\
\hline & & $\begin{array}{l}\text { Límite } \\
\text { inferior }\end{array}$ & $\begin{array}{l}\text { Límite } \\
\text { superior }\end{array}$ & \\
\hline Constante & 12.527 & -3.229 & 27.886 & 0.111 \\
\hline $\begin{array}{l}\text { Días entre el primer } \\
\text { caso diagnosticado } \\
\text { y la prohibición } \\
\text { de eventos y } \\
\text { concentraciones }\end{array}$ & -0.672 & -1.429 & 0.079 & 0.080 \\
\hline $\begin{array}{l}\text { Días entre el primer } \\
\text { caso diagnosticado } \\
\text { y el cierre de } \\
\text { fronteras }\end{array}$ & 1.421 & 0.672 & 2.175 & $0.001 *$ \\
\hline $\begin{array}{l}\text { Camas hospitalarias } \\
\text { por cada } 1000 \\
\text { habitantes }\end{array}$ & -3.016 & -5.820 & -0.192 & $0.037 *$ \\
\hline
\end{tabular}

Estas medidas deben acompañarse de distanciamiento social y de la realización de una prueba diagnóstica en los casos en los que se sospeche infección. La implantación de medidas de este tipo ha conseguido una reducción gradual del número de casos en tres a cuatro semanas. ${ }^{16}$

Asumiendo que las medidas estrictas de distanciamiento y confinamiento contribuyen al descenso del número de casos y, en consecuencia, de fallecimientos, los siguientes pasos deben estar dirigidos a cómo desescalar las medidas restrictivas impuestas. Si se finalizara prematuramente la cuarentena debido a los enormes costos sociales y económicos del confinamiento, se volvería al escenario de inicio donde la epidemia se extiende nuevamente de forma exponencial. ${ }^{17}$

\section{Conclusiones}

Un sistema sanitario adecuado, unos profesionales bien formados y unas medidas restrictivas y de distanciamiento social adecuadas son esenciales para disminuir el número de contagios de COVID-19, así como sus tasas de mortalidad. Cuanto más precoces sean las medidas restrictivas instauradas, menor será la cantidad de fallecimientos debidos a infección por SARS-CoV-2.

\section{Conflicto de intereses}

Los autores declaran no tener conflicto de intereses alguno.

\section{Financiamiento}

La presente investigación no recibió ninguna beca específica de agencias de los sectores públicos, comercial o sin ánimo de lucro.

\section{Responsabilidades éticas}

Protección de personas y animales. Los autores declaran que para esta investigación no realizaron experimentos en seres humanos ni en animales.

Confidencialidad de los datos. Los autores declaran que en este artículo no aparecen datos de pacientes.

Derecho a la privacidad y consentimiento informado. Los autores declaran que en este artículo no aparecen datos de pacientes. 


\section{Bibliografía}

1. Zhu N, Zhang D, Wang W, Li X, Yang B, Song J, et al. A novel coronavirus from patients with pneumonia in China, 2019. N Engl J Med. 2020;382:727-733.

2. Ji W, Wang W, Zhao X, Zai J, Li X. Cross-species transmission of the newly identified coronavirus 2019-nCoV. J Med Virol. 2020;92:433-440.

3. Zhang Y. [The epidemiological characteristics of an outbreak of 2019 novel coronavirus diseases (COVID-19) in China]. Zhonghua Liu Xing Bing Xue Za Zhi. 2020;41(2):145-151.

4. Zhou P, Yang XL, Wan XG, Hu B, Zhang L, Zhang W, et al. A pneumonia outbreak associated with a new coronavirus of probable bat origin. Nature. 2020;579:270-273

5. Chen L, Liu W, Zhang Q, Xu K, Ye G, Wu W, et al. RNA based mNGS approach identifies a novel human coronavirus from two individual pneumonia cases in 2019 Wuhan outbreak. Emerg Micro Infect. 2020;9:313-319.

6. Wu A, Peng Y, Huang B, Ding X, Wang X, Niu P, et al. Genome composition and divergence of the novel coronavirus (2019-nCoV) originating in China. Cell Host Microbe. 2020;27:325-328.

7. Carod-Artal FJ. Complicaciones neurológicas por coronavirus y $\mathrm{CO}$ VID-19. Rev Neurol. 2020;70: 311-322.

8. Mamoon N, Rasskin G. Covid visualizer. EE.UU.: Carnegie Mellon University [Internet]; 2020.
9. Barcelona Centre for International Affairs [Internet]. España: COVID-19: la respuesta de Europa contra la pandemia; 2020.

10. Johns Hopkins University/Coronavirus Resource Center [Internet]. EE. UU.: Mortality analyses; 2020.

11. Banco Mundial [Internet]. EE. UU.: Médicos por cada 1000 personas; 2020.

12. Banco Mundial [Internet]. EE. UU.: Camas hospitalarias por cada 1000 personas; 2020.

13. Organización Mundial de la Salud. [Internet]. Suiza: Consideraciones relativas a los ajustes de las medidas de salud pública y sociales en el contexto de la COVID-19; 2020.

14. Ferguson NM, Laydon D, Nedjati-Gilani G, Imai N, Ainslie K, Baguelin M, et al. Report 9 - Impact of non-pharmaceutical interventions (NPIs) to reduce COVID19 mortality and healthcare demand. Reino Unido: Imperial College London; 2020.

15. Nussbaumer-Streit B, Mayr V, Dobrescu Al. Quarantine alone or in combination with other public health measures to control COVID-19: a rapid review. Cochrane Database Syst Rev. 2020;4:CD013574.

16. Mitjà $\mathrm{O}$, Arenas $A$, Rodó $X$. Experts' request to the Spanish Government: move Spain towards complete lockdown. Lancet. 2020;395:1193-1194.

17. Prem K, Liu Y, Russell TW, Kucharski AJ, Eggo RM, Davies N, et al. The effect of control strategies to reduce social mixing on outcomes of the COVID-19 epidemic in Wuhan, China: a modelling study. Lancet Public Health. 2020;5:e261-e270. 